\title{
Investigation of the Performance and Kinetics of Anaerobic Digestion at $45^{\circ} \mathrm{C}$
}

\author{
Nuruol Syuhadaa Mohd1, Taqsim Husnain², Baoqiang Li², Arifur Rahman², Rumana Riffat ${ }^{2}$ \\ ${ }^{1}$ Department of Civil Engineering, University of Malaya, Kuala Lumpur, Malaysia \\ ${ }^{2}$ Department of Civil and Environmental Engineering, George Washington University, Washington DC, USA \\ Email: riffat@gwu.edu
}

Received 10 July 2015; accepted 19 September 2015; published 22 September 2015

Copyright (C) 2015 by authors and Scientific Research Publishing Inc.

This work is licensed under the Creative Commons Attribution International License (CC BY).

http://creativecommons.org/licenses/by/4.0/

(c) (i) Open Access

\section{Abstract}

The objective of this study was to evaluate the performance of anaerobic digestion (AD) within the intermediate zone, specifically at $45^{\circ} \mathrm{C}$. Single-stage batch anaerobic digestion system was developed in the lab and performance was monitored for more than 2 years. The AD system was able to achieve high biogas production with about $62 \%$ - $67 \%$ methane content. The digester exhibited high acetate accumulation, but sufficient buffering capacity was observed as the $\mathrm{pH}$, alkalinity and volatile fatty acids-to-alkalinity ratio were within recommended values. The system achieved $36.5 \%$ reduction of total solids (TS) and $47.8 \%$ reduction of volatile solids (VS), which exceeded the required VS destruction efficiency for Class A biosolids. The pathogen counts were less than 1000 MPN/g total solids in the effluent, which also satisfied Class A biosolids requirements. The accumulation of acetate was presumably due to the high temperature which contributed to high hydrolysis rate. Consequently, it produced large amount of toxic salts that combined with the acetate, making them not readily available to be consumed by methanogens. The slower degradation of acetate was observed by the kinetic parameters. Accumulation of acetate contributed to $52 \%$ to $\mathbf{7 1 \%}$ reduction in acetate degradation process, but was not completely inhibitory. The methanogens existing in the system were mostly thermo-tolerant acetate-utilizing methanogens, and specifically from Methanosarcinaceae species.

\section{Keywords}

Anaerobic Digestion, Acetate Accumulation, Salt Toxicity, Inhibition Kinetics

\section{Introduction}

Anaerobic digestion has been the most widely used method for the degradation and stabilization of domestic and

How to cite this paper: Mohd, N.S., Husnain, T., Li, B.Q., Rahman, A. and Riffat, R. (2015) Investigation of the Performance and Kinetics of Anaerobic Digestion at $45^{\circ} \mathrm{C}$. Journal of Water Resource and Protection, 7, 1099-1110.

http://dx.doi.org/10.4236/jwarp.2015.714090 
industrial wastes for many years. This process has received increased attention in the recent years due to global energy crisis, as anaerobic digestion has great potential for producing energy-rich biogas and nutrient-rich biosolids. Strict environmental regulations for pollutant minimization also demonstrated the need of anaerobic digestion for safe and effective method of organic waste disposal.

Anaerobic digestion (AD) is a biological process that converts complex substrates into biogas and digestate by microbial action in the absence of oxygen through four main steps, namely hydrolysis, acidogenesis, acetogenesis and methanogenesis [1]. Anaerobic digestion of wastewater sludge has generally been conducted within the mesophilic temperature range of $30^{\circ}-40^{\circ} \mathrm{C}$ or thermophilic temperature range of $55^{\circ}-60^{\circ} \mathrm{C}$. The mesophilic system is often preferred due to its good operational performances, good effluent quality, higher degree of stability and comparatively low energy requirement. Despite that, mesophilic anaerobic digestion usually requires long retention time, produces insufficient reduction of volatile solids and deactivates insufficient amount of pathogens [2]-[4]. To overcome the limitations, thermophilic anaerobic digestion has been the technology of choice due to enhanced hydrolysis of complex organic materials, higher solids destruction efficiency, better dewatering capability, ability to sustain higher loading of waste, reduction in foaming and most importantly the production of biosolids that meets United States Environmental Protection Agency (U.S. EPA) Class A biosolids specifications [5]-[7]. However, several studies have reported that the slightly higher rates of hydrolysis and fermentation in thermophilic digesters have not necessarily led to a higher methane yield and can be disadvantageous due to large amount of energy required for heating, the increased sensitivity to environmental factors and poor effluent quality with high volatile fatty acids (VFA) content [2] [6] [7].

Although a large number of researchers have addressed the performance of mesophilic and thermophilic anaerobic digestion, very few studies have investigated the possibility of operating anaerobic digestion in the intermediate zone between mesophilic and thermophilic range. This is based on the assumption that limited microbial activity occurs within the intermediate zone of $40^{\circ}-50^{\circ} \mathrm{C}$ due to the fact that neither mesophilic nor thermophilic microorganisms would flourish in the intermediate zone, as the microorganisms are trying to cope with the changing environment, hence causing the digestion to slow down [8]. However, few recent studies have triggered questions regarding its validity as $45^{\circ} \mathrm{C}$ anaerobic digestion system was still producing gas and was significantly similar, or even higherthan the mesophilic system [4] [9]. Good effluent quality in terms of COD removal efficiency, ranging from $81.5 \%$ to $91.2 \%$, was observed using $45^{\circ} \mathrm{C}$ digester [10] and there was no great variation between anaerobic digestion systems operating at $37^{\circ} \mathrm{C}$ and $45^{\circ} \mathrm{C}$ in terms of methane production, volatile solids (VS) content and $\mathrm{pH}$, except for VFA concentration that increased significantly with increasing temperature [11]. Ref. [12] exhibited a significant increase in VS removal with the rise in temperature and approaches a plateau at $45^{\circ} \mathrm{C}$. The degree of acidification (VFA/tCOD) was highest at $45^{\circ} \mathrm{C}$ and was chosen as optimum temperature for acidogenic phase [13]. However, none of these studies have done any further investigation in finding the reasons behind the accumulation of VFAs observed in their digestion system, as well as the capability of the system to produce Class A biosolids. The above findings imply that microbial activities are still occurring within the intermediate zone, and thus it is necessary to further investigate whether they are mesophilic activities, or thermophilic activities, or possibly activities involving both types of microorganisms.

According to U.S. EPA, Class A biosolids can only be produced through treatment processes involving high temperatures such as thermophilic anaerobic digestion [14]. The motivations for this research were, if the $45^{\circ} \mathrm{C}$ anaerobic digestion system could produce comparable amount of methane as the mesophilic digester, and could generate same quality of biosolids as thermophilic digester, there could be significant economic benefits by operating the digester at $45^{\circ} \mathrm{C}$, in comparison to the conventional thermophilic digester. This study investigated the performance of anaerobic digestion within the intermediate zone, specifically at $45^{\circ} \mathrm{C}$, and the potential for generating Class A biosolids. In addition, the possible inhibition kinetics for the accumulation of VFAs at higher temperature was also analyzed.

\section{Materials and Methods}

\subsection{Anaerobic Digester Setup}

Two single-stage batch anaerobic digestion systems were constructed and operated in parallel, where the second system served as a duplicate. The digester was made of high density polyethylene (HDPE) $25 \mathrm{~L}$ brewery tanks of Hobby Beverage Equipment Company (Temecula, California). The temperature of the digester was maintained at $45^{\circ} \mathrm{C}$ with a heating system controlled by a thermostat connected to a temperature sensor inserted into 
the digester. The digester was covered with aluminum foil and temperature adjustable heating tape was placed on top of the foil to ensure even heat distribution to the digester and to provide protection from the heating tape so that physical failure of the polyethylene would not occur. Gas mixing was applied by circulating the headspace gas to the bottom of the digester by using a peristaltic pump (Cole-Parmer, Vernon Hills, IL). The digester was equipped with a gas collection flask and Wet Tip gas meter (Nashville, TN) to measure volume of gas production. Figure 1 shows the schematic diagram of the anaerobic digestion system.

\subsection{Digester Start-Up and Operations}

The anaerobic digester system was initiated by inoculating with seed sludge from well operating mesophilic anaerobic digester in Alexandria Wastewater Treatment Plant, AlexRenew (Alexandria, VA). This was done to benefit from the seed sludge that usually contains abundant amounts of microorganisms such as methane formers and acid forming bacteria. After approximately 3 days of seed feeding, the digester system was fed with raw municipal sludge obtained from Blue Plains Advanced Wastewater Treatment Plant (Washington, DC). The raw sludge was the effluent after the thickening process. During this initial phase, no effluents were taken out as the microorganisms need to have ample time to establish themselves within the new environment. After approximately two weeks, duration that was considered sufficient for microorganisms' adaptation, the feeding and effluent withdrawing schedules were started. The digester was fed once a day and an equal amount of digested sludge or effluent was withdrawn directly before feeding.

The operational volume of the anaerobic digester was $15 \mathrm{~L}$. The total solids (TS) content of the feed sludge (influent) was $6.5 \%$ with an average organic loading rate (OLR) of $5.22 \mathrm{kgVS} / \mathrm{m}^{3} \cdot \mathrm{d}$. The feed sludge was acclimated to the desired temperature of $45^{\circ} \mathrm{C}$ by incubating for approximately $2 \mathrm{~h}$ before feeding. The solid retention time (SRT) of $10 \mathrm{~d}$ was selected for the digester, which is regarded as optimum time for the methanogens to complete the digestion process. Because the digester was kept completely mixed throughout the study, and

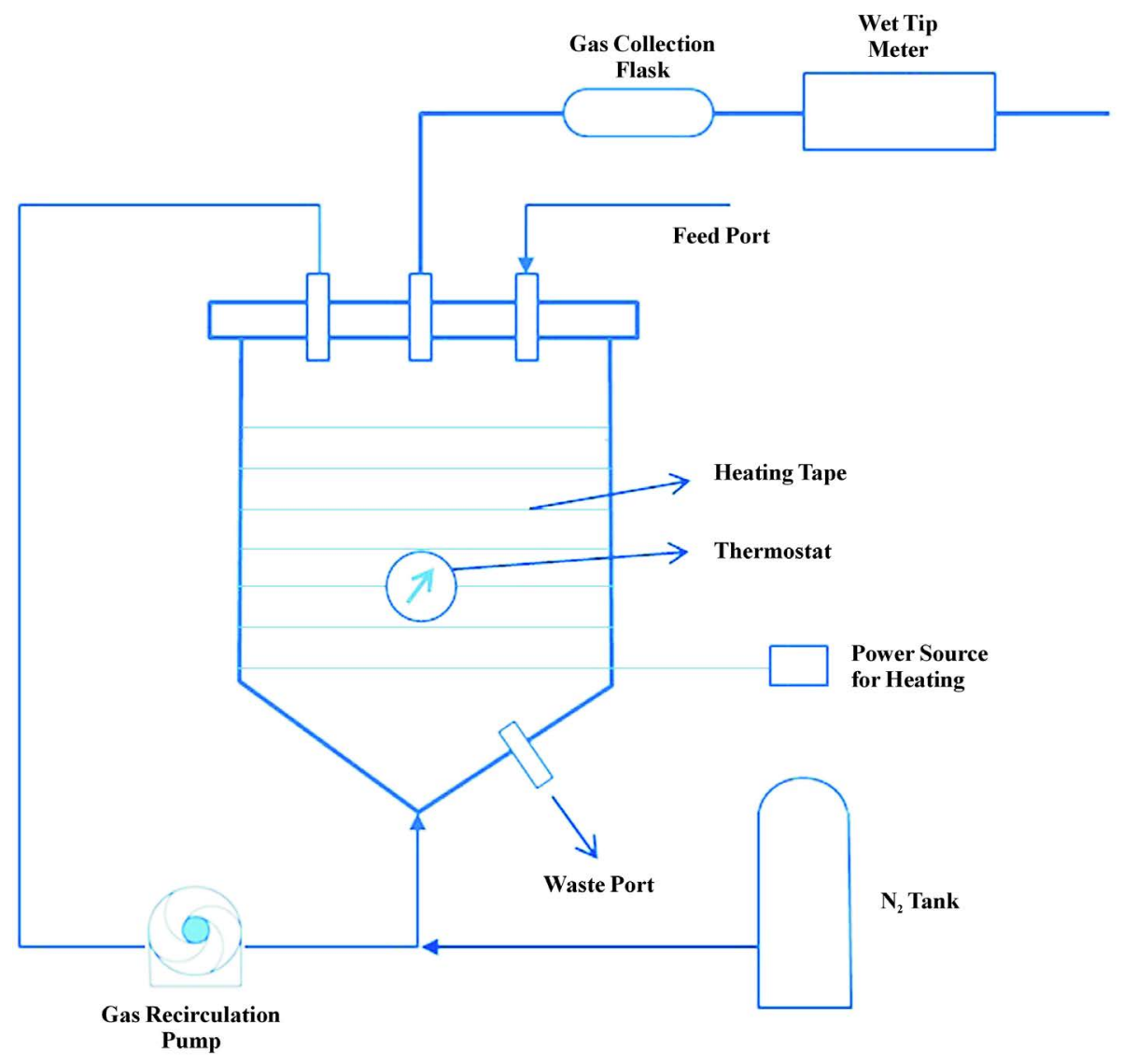

Figure 1. Schematic diagram of anaerobic digestion system. 
feeding and wasting were done in equal amounts, solids retention time (SRT) of the reactor was equal to hydraulic retention time (HRT).

Inorganic nutrients in the form of chloride salts were added into the anaerobic digester systems, as an initiative to increase the rate of anaerobic metabolism in term of methane gas production and low VFA accumulation [6] [15]. Typically, the feed may contain more than ample nutrients, but its bioavailability can be limiting due to precipitation reactions occurring during the digestion process. Table 1 lists the inorganic nutrients prepared from the chloride salts (Acros Organics, NJ). $2 \mathrm{~mL}$ of each nutrient was added to the feed sludge before the feeding process.

\subsection{Experimental Methods}

The operating parameters of the feed and digested sludge were analyzed regularly for more than 2 years of operations. The $\mathrm{pH}$ was measured daily, while the alkalinity, total solids (TS), volatile solids (VS), soluble COD (sCOD), total COD (tCOD), total ammonia nitrogen (TAN) and volatile fatty acids (VFA) were analyzed weekly. Alkalinity, TS, VS, COD and TAN tests were conducted in accordance to Standard Methods 2320 B, 2540 B, 2540 E, 5220 D and 4500- $\mathrm{NH}_{3}$ B \& C, respectively [16]. VFA was analyzed using a Shimadzu Gas Chromatograph Model GC-2010 (Shimadzu, Columbia, MD) with flame ionization detector (FID) and equipped with a RestekStabilwaxfi-DA capillary column. The column temperature was $145^{\circ} \mathrm{C}$, and the injector and flame ionization detector temperature was $250^{\circ} \mathrm{C}$. The calibration curves were obtained using five aqueous solutions of organic acids: acetic, propionic, butyric, valeric and caproic, in the concentration range of 25 to $1000 \mu \mathrm{L} / \mathrm{L}$. The feed and digested sludge was analyzed for pathogens using MPN Method as described in EPA Method 1680 [17]. The total biogas production was monitored daily using a Wet Tip gas meter (Nashville, TN) and gas composition was analyzed using SRI 8610 C Gas Chromatograph (SRI Instruments, Torrance, CA) equipped with a flame ionization detector (FID) with Helium as the carrier gas. Sludge samples from the digesters were sent to MRDNA laboratory (Shallowater, TX) for methanogen Illumina Assays, to obtain the methanogen species and counts.

\subsection{Batch Kinetic Tests}

The effluent from the digester was collected and used as a sample for batch kinetic tests. The effluent was first diluted to eliminate the possible inhibition effects of existing soluble compounds such as ammonia and acetate. Subsequently, the samples were mixed and placed in $500 \mathrm{~mL}$ glass bottles. The temperature was controlled and the headspace was flushed with nitrogen gas to create anaerobic condition within the vessel. The substrate (acetic acid) was added in a diluted form of synthetic acetic acid $2.0 \mathrm{~N}$ (Fisher Chemical, Pittsburgh, PA) to the samples. The tests were conducted using $400 \mathrm{~mL}$ of digester effluent, mixed at least once a day using a magnetic stirrer and incubated at $45^{\circ} \mathrm{C}$. The concentrations of the remaining acetate were observed for every $30 \mathrm{~min}$ to $1 \mathrm{~h}$ intervals and the tests were conducted until all acetate has been harvested or when there is no further destruction of the remaining acetate.

During the kinetic tests, the concentrations of remaining unionized acetate, $S$ at different sampling time, $t$ was collected. Unionized acetate progress curve was plotted and the model was developed to fit these curves. The kinetic coefficients were determined using a Monod-based model [18].

The Monod model is shown in Equation (1), and the model proposed by Ref. [18] is presented in Equation (2).

\begin{tabular}{cc|}
\begin{tabular}{c} 
Table 1. Trace mineral solution recipe for the anaerobic digestion system. \\
\hline Inorganic nutrients
\end{tabular} & Concentration $(\mathrm{g} / \mathrm{L})$ \\
\hline $\mathrm{FeCl}_{2} \cdot 4 \mathrm{H}_{2} \mathrm{O}$ & 35.6 \\
$\mathrm{ZnCl}_{2}$ & 2.08 \\
$\mathrm{NiCl}_{2} \cdot 6 \mathrm{H}_{2} \mathrm{O}$ & 4.05 \\
$\mathrm{CoCl}_{2} \cdot 6 \mathrm{H}_{2} \mathrm{O}$ & 4.04 \\
$\mathrm{MnCl}_{2} \cdot 4 \mathrm{H}_{2} \mathrm{O}$ & 3.61 \\
\hline
\end{tabular}




$$
\mu=\mu_{\max } \frac{S}{K_{s}+S}
$$

where $\mu, \mu_{\max }$ and $S$ are specific growth rate $\left(t^{-1}\right)$, maximum specific growth rate $\left(t^{-1}\right)$ and concentration of growth-limiting substrate $(\mathrm{mg} / \mathrm{L})$, respectively. $K_{s}$ is half saturation constant, substrate concentration at one-half the maximum growth rate. In the model, the best estimates of the kinetic coefficients and constant can be determined by minimizing differences between model predictions to observed experimental values of sampling time $t$ using Equation (2).

$$
t=\left[-\frac{Y}{r_{\max }}\right]\left[K_{s} \cdot \ln \frac{S}{S_{0}}+S-S_{0}\right]
$$

where $Y$ is the yield coefficient $(\mathrm{mg} / \mathrm{mg})$, and $r_{\max }$ is the maximum bacterial growth rate $(\mathrm{mg} / \mathrm{L} \cdot \mathrm{d})$. The model predictions of $t$ were calculated by using the known value of $Y$ together with initial estimates of the parameters that are sought (i.e. $K_{s}, r_{\max }$ and $S_{0}$ ). In this model, $S_{0}$ was also used as a fitting parameter because it was not known with greater certainty than the other data points, thus, it would not be appropriate to force the best-fit curve through the measured value of $S_{0}$ [18]. The best fit was obtained with Solver function in Microsoft Excel, which used an iterative search for the parameter values that yielded the minimum square errors, and the initial estimates of the parameters were automatically replaced by the parameters best estimates.

The inhibition kinetic coefficient, $K_{I}$ and dimensionless inhibition concentration, $I_{\mathrm{HAc}}$, were determined using a Michaelis-Menten model [19]. Equation (3) shows the basis of the model.

$$
v=-\frac{\mathrm{d} S}{\mathrm{~d} t}=\frac{V_{m} \cdot S}{K_{m}+S}
$$

where $v$ is the rate of substrate utilization (substrate/unit volume time), $V_{m}$ is the maximum specific rate $\left(t^{-1}\right)$ and $K_{m}$ is the substrate utilization constant or saturation constant (mg/L). Detail parameter estimation process using the extended version of the model, depending on the type of inhibition, are available in [19].

\section{Results and Discussions}

\subsection{Performance of Anaerobic Digestion at $45^{\circ} \mathrm{C}$}

The performance of the anaerobic digestion (AD) at $45^{\circ} \mathrm{C}$ was assessed based on methane gas production, methane yield, biogas composition, ammonia content, VFA content, buffering capacity, TS and VS reductions, soluble and total COD reductions as well as pathogen destruction. Daily methane production of the anaerobic digester is illustrated in Figure 2. In general, increasing trends of methane gas over time was observed in the system indicating

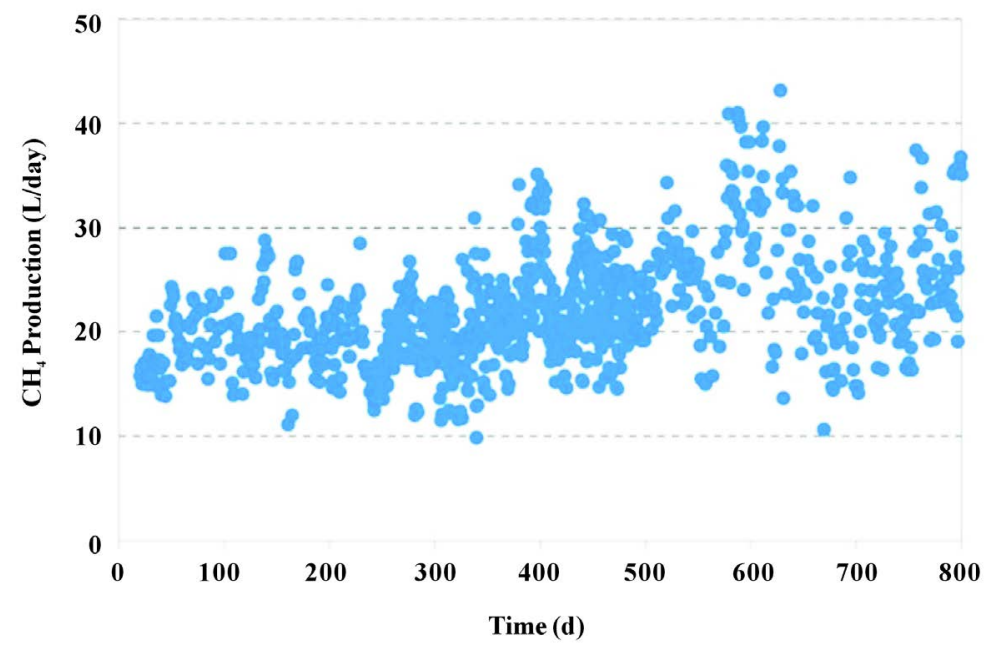

Figure 2. Methane production of $45^{\circ} \mathrm{C}$ anaerobic digestion system. 
that as the days progressed, the microbes had established, flourished and expanded their colonies, hence, contributed to the gradual increase of methane production.

The specific methane yield for the AD system was $0.56 \pm 0.04 \mathrm{~m}^{3} \cdot \mathrm{CH}_{4} / \mathrm{kgVS}$ removed, which is within the lower end of the recommended range of 0.60 to $1.60 \mathrm{~m}^{3} \cdot \mathrm{CH}_{4} / \mathrm{kgVS}$ removed [20]. The composition of methane in the headspace gas was 66.08 percent which is comparable to the values for mesophilic digesters found in the literatures. The absence of any clear and sharp decline of gas production at $45^{\circ} \mathrm{C}$ implies that there may not be a transition zone between mesophilic and thermophilic zones that inhibit the methane forming activity. Instead, as mesophilic methane formers exist in mesophilic zone, and thermophilic methane formers exist in thermophilic zone, there might be an overlap between these two zones that still allow methane formation by both types of microorganisms. The lower methane yield of the $45^{\circ} \mathrm{C} \mathrm{AD}$ system can be associated to its operation within the intermediate zone of mesophilic and thermophilic, therefore not providing an optimum growth environment for either type of methane formers, and subsequently affecting the amount of methane produced.

Since inhibition of the anaerobic digestion system is primarily indicated by the levels of total ammonia (TAN) and free ammonia generated within the system, therefore both were measured in the study. The average TAN and free ammonia concentrations were found to be $1735 \mathrm{mg} / \mathrm{L}$ and $83 \mathrm{mg} / \mathrm{L}$, respectively. The TAN concentrations were slightly higher than the lower limit of the inhibitory region of 1500 and $3000 \mathrm{mg} / \mathrm{L}$ [21], whereas the level of free ammonia was lower than the inhibitory level of 100 to $150 \mathrm{mg} / \mathrm{L}$ [22]. The higher TAN concentrations may have exerted a detrimental effect on the methanogens, particularly on the acetate-utilizing methane formers. However, inhibition was not observed, as the $45^{\circ} \mathrm{C}$ digesters have been operated for more than 2 years with sufficient VS destruction and methane production, as well as stable $\mathrm{pH}$ levels. A gas chromatographic analysis of the VFA in AD system showed that they consisted of acetate, propionate, butyrate and valerate, with the first two being the predominant components. As acetate accounted for a significant majority of the total VFA concentration, it was thus the most sensitive VFA indicator of digester operation. The average concentrations of all types of VFAs for the feed and digester effluent are presented in Figure 3.

Buffering capacity is also a crucial indicator of the well-being of anaerobic digester. The average $\mathrm{pH}$ and alkalinity of the digester were 7.41 and 10,082 mg/L, respectively. $\mathrm{pH}$ value was within high end of the operable $\mathrm{pH}$ range value of 6.6 - 7.6 [23]. The increased $\mathrm{pH}$ value in $45^{\circ} \mathrm{C} \mathrm{AD}$ was due to reduced solubility of carbon dioxide at higher temperature. With regard to alkalinity, an anaerobic digestion system requires an alkalinity of at least $1500 \mathrm{mg} / \mathrm{L}$ in the presence of biogas containing about 30 percent carbon dioxide [24]. Within the AD system, the alkalinity was observed to be as high as $10,000 \mathrm{mg} / \mathrm{L}$ and apparently, high alkalinity was favorable as it provided effective buffering against a $\mathrm{pH}$ drop due to the accumulation of VFAs. Higher alkalinity usually indicates a greater amount of protein conversion resulting in high ammonia content as well as salts. In a digester, these salts produce natural buffers, which normally remain fairly constant at about 3000 to $4000 \mathrm{mg} / \mathrm{L}$ [25].

Additionally, other than ammonia and salts, the increase in alkalinity was also attributed to its high

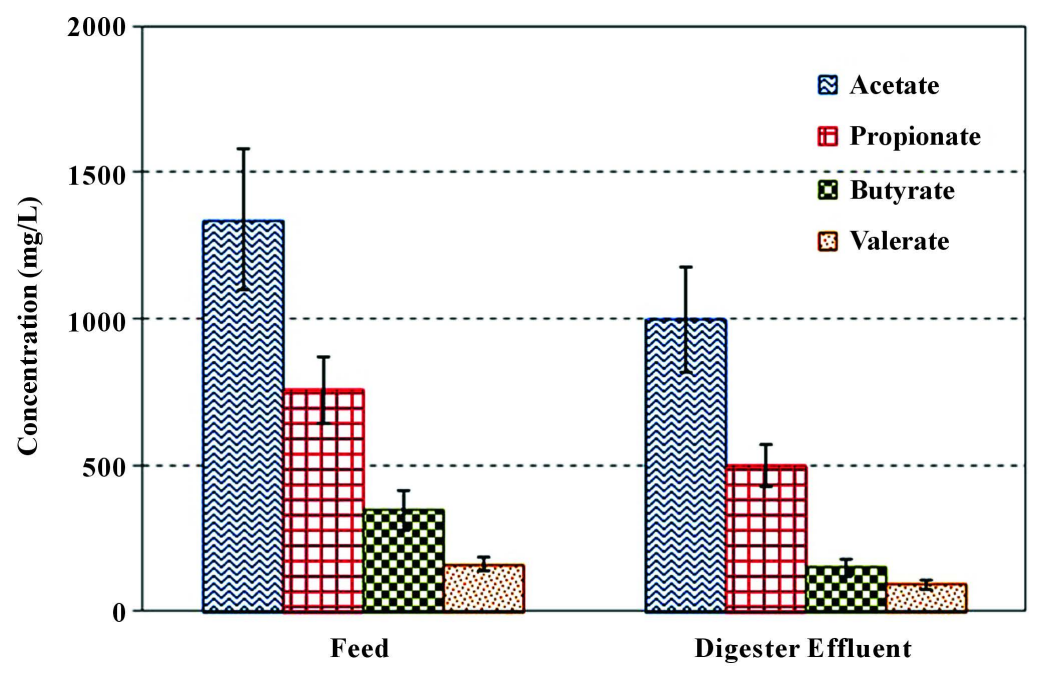

Figure 3. Acetate, propionate, butyrate and valerate composition of anaerobic digestion system. 
concentration of VFA observed in $45^{\circ} \mathrm{C}$ systems. As VFA concentrations began to increase, they are neutralized by the bicarbonate alkalinity, thus, forming volatile acid alkalinity [23]. Therefore, instead of only having bicarbonate alkalinity, which is normally observed in mesophilic systems, the $45^{\circ} \mathrm{C}$ systems now had total alkalinity composed of bicarbonate alkalinity and volatile acid alkalinity. As a result, the VFA-to-alkalinity ratio, an estimate to enumerate the ability of the system's capacity to cope with rapid change in $\mathrm{pH}$, was 0.16 which is well below the suggested inhibition value of 0.4 [26].

With regard to the ability of the digester for reducing TS and VS content, the system was able to achieve 36.5\% reduction of TS and $47.8 \%$ reduction of VS, which exceed the required average VS destruction efficiency of $45 \%$ for Class A biosolids criterion for vector attraction reduction [27]. High TS and VS reductions in $45^{\circ} \mathrm{C}$ system implied an increase in dewatering capabilities of the digested effluent due to its reduced viscosity and a better separation of solids. In addition to that, it also suggested an increase in sludge reduction as well as sufficient sludge stabilization.

The system was able to achieve significantly high reduction of soluble COD (sCOD), total COD (tCOD) and pathogen from the feed, as presented in Table 2. Pathogenic bacteria are an important factor to consider, if the sludge is to be used as a fertilizer or soil amendment. The $\mathrm{AD}$ system at $45^{\circ} \mathrm{C}$ had successfully achieved 3-log reduction of fecal coliforms, which is very difficult to achieve by the traditional mesophilic digester at $35^{\circ} \mathrm{C}$. The concentration of fecal coliforms in the digested sludge never exceeded $1000 \mathrm{MPN} / \mathrm{g}$ total solids, thus met the U.S. federal fecal coliform requirements for Class A biosolids [27]. The higher deactivation of pathogens was probably a result of the combined effects of high temperature, VFA, TAN, free ammonia and long retention time.

\subsection{Acetate Accumulation in Anaerobic Digestion at $45^{\circ} \mathrm{C}$}

Anaerobic digester at $45^{\circ} \mathrm{C}$ produced significantly high acetate accumulation, as shown in Figure 3, due to high hydrolysis rate at higher temperature. In some cases, they were even higher than the feed itself, even though methane was continuously produced throughout the process. They were four reasons that possibly contributed to this situation. First, at higher temperature, more proteinaceous materials were degraded and created ammonia-stress condition which had a negative influence on acetate-utilizing methanogens in comparison to the other microbes (i.e. acetate-producing acidogens). As a result, acetate was produced faster than they could be utilized, hence allowing them to accumulate within the system. Second, the abundance of acetate in the effluent suggested that instead of functioning as a fully methanogenic digester, it was serving more as an acid-phase digester. In other words, the methanogenesis process had not reached a complete steady state yet. If more time were to be given to the methanogens, more appreciable acetate reduction would be expected. Third, at $45^{\circ} \mathrm{C}$, instead of acting as a transition zone that inhibits microbial activity, there might be an overlap between these two zones that allow the methane to be formed despite the accumulation of VFA. The said methane formers might be the hydrogen-utilizing thermophilic methanogens instead of acetate-utilizing mesophilic methanogens. Presumably, the colonies of hydrogen-utilizing thermophilic methanogens which was at its optimum at higher temperature, were more abundant in number, hence leaving the other methanogens' substrate, acetate, not fully utilized. Lastly, it might also be caused by the way the digester was started up. The $45^{\circ} \mathrm{C}$ digester was started up by increasing the temperatures slowly from the mesophilic operating temperature. This technique was likely to lead to the development of a population that was different from a population obtained through a true thermophilic digester.

The population was most probably a thermo-tolerant acetate-utilizing mesophilic methanogens, a mesophile that can survive at high temperature but whose optimum growth rate occurs at mesophilic temperatures [28]. Thus, the operating temperature of $45^{\circ} \mathrm{C}$ might not be the optimum temperature for the microbes, hence affecting

Table 2. Soluble COD, total COD and pathogen removel efficiency of the anaerobic digester.

\begin{tabular}{cccc}
\hline Inorganic nutrients & Feed $(\mathrm{mg} / \mathrm{L})$ & Digester effluent $(\mathrm{mg} / \mathrm{L})$ & \% Reduction \\
\hline Soluble COD & $11057 \pm 1578$ & $7012 \pm 639$ & 37.41 \\
Total COD & $74250 \pm 6183$ & $46232 \pm 3380$ & 38.25 \\
Pathogen count & $7.16 \times 10^{6}$ & $2.52 \times 10^{2}$ & $>99.99$ \\
\hline
\end{tabular}


their methanogenic activity. At $45^{\circ} \mathrm{C}$ AD system, the population of true acetate-utilizing mesophilic methanogens or thermo-tolerant acetate-utilizing mesophilic methanogens were gradually diminishing, due to the high ammonia content and high temperature, hence, leaving more acetate unutilized.

As for the presence of propionate, though was commonly believed to also inhibit methanogenesis, the concentrations were well below the tolerable range of $800 \mathrm{mg} / \mathrm{L}$ to $3000 \mathrm{mg} / \mathrm{L}$ [15] [29], whereas the presence of butyrate and valerate were remained minimal in the digester.

\subsection{Kinetics of Acetate Accumulation}

A series of kinetic tests were performed in order to investigate the accumulation and inhibitory effect of acetate despite the abundant generation of methane in $45^{\circ} \mathrm{C}$ anaerobic digestion system. The comparisons were made between systems containing different sources of acetate, one was found naturally in the system, while the other one, was added in a form of acetic acid to the system. In this study, the former was termed as background acetate (B/g HAc) or salt-originated-acetate and the later was termed as added acetate (HAc) or acetic acid-originated-acetate. Four sets of experiments were conducted varying the concentration of background acetate and added acetate, and corresponding kinetic parameters are summarized in Table 3.

Figure 4 presents the progress curve of acetate degradation at different background acetate (B/g HAc) concentration of 500, 1000 and $1500 \mathrm{mg} / \mathrm{L}$. All the kinetic parameter values in the system were decreasing as the background acetate concentration increased, as shown in Table 3, indicating slower acetate degradation at higher concentration. Figure 5 shows the progress curve of acetate degradation with and without the added acetate (HAc). Observing Figure 4 and Figure 5, it was clear that the system with added acetate degraded faster than the system with background acetate source. This observation was evidenced by its $K_{s}, r_{\max }$ and $I_{\mathrm{HAc}}$ values which were higher in the system with added acetate in comparison to the system with background acetate.

Figure 6 compares the acetate degradation by individually considering the background acetate (B/g HAc) and added acetate (HAc), and showed that almost negligible acetate left in the case with added acetate in comparison to more than $400 \mathrm{mg} / \mathrm{L}$ acetate left in the case with background acetate. Such distinct differences in the degradation pattern with different sources of acetate are explained below.

In anaerobic digestion process, hydrolysis is always rate limiting [30], i.e. organic materials in solid portion of the sludge are slowly hydrolyzed and brought into solution by the microorganisms present in the digester. Under optimal operating conditions, the organic matter is broken down into VFAs by acid formers, and decomposed rapidly into carbon dioxide and methane by methane formers. During the process, there is a buildup of certain salts in solution such as ammonium, calcium, magnesium, potassium and sodium resulting from the break-up of proteins. As the cations of salts in solution must always be associated with the anions, it might possibly be bonded with the acetate produced from acidogenesis, hence contribute significantly in the generation of acetate

Table 3. Model-estimated kinetic parameters at different acetate concentrations.

\begin{tabular}{|c|c|c|c|c|}
\hline & $S_{o}(\mathrm{mg} / \mathrm{L})$ & $r_{\max }(\mathrm{mg} / \mathrm{L} /$ day $)$ & $K_{s}(\mathrm{mg} / \mathrm{L}$ as $\mathrm{HAc})$ & $I_{\mathrm{HAc}}$ \\
\hline \multicolumn{5}{|l|}{$\underline{\text { Run } 1}$} \\
\hline $\mathrm{B} / \mathrm{g} \mathrm{HAc}+\mathrm{HAc}=500+0 \mathrm{mg} / \mathrm{L}$ & 0.41 & 0.04 & 101 & 0.48 \\
\hline $\mathrm{B} / \mathrm{g}$ HAc $+\mathrm{HAc}=500+1000 \mathrm{mg} / \mathrm{L}$ & 1.31 & 0.14 & 237 & 1.36 \\
\hline \multicolumn{5}{|l|}{$\underline{\operatorname{Run} 2}$} \\
\hline $\mathrm{B} / \mathrm{g} \mathrm{HAc}+\mathrm{HAc}=1000+0$ mg/L & 0.87 & 0.03 & 60 & 0.33 \\
\hline $\mathrm{B} / \mathrm{g} \mathrm{HAc}+\mathrm{HAc}=1000+1000 \mathrm{mg} / \mathrm{L}$ & 1.62 & 0.13 & 279 & 1.26 \\
\hline \multicolumn{5}{|l|}{$\underline{\operatorname{Run} 3}$} \\
\hline $\mathrm{B} / \mathrm{g} \mathrm{HAc}+\mathrm{HAc}=1500+0 \mathrm{mg} / \mathrm{L}$ & 1.12 & 0.03 & 60 & 0.29 \\
\hline $\mathrm{B} / \mathrm{g} \mathrm{HAc}+\mathrm{HAc}=1500+1000 \mathrm{mg} / \mathrm{L}$ & 2.37 & 0.10 & 257 & 0.98 \\
\hline \multicolumn{5}{|l|}{$\underline{\text { Run } 4}$} \\
\hline $\mathrm{B} / \mathrm{g} \mathrm{HAc}+\mathrm{HAc}=1000+0 \mathrm{mg} / \mathrm{L}$ & 0.87 & 0.03 & 61 & 0.33 \\
\hline $\mathrm{B} / \mathrm{g} \mathrm{HAc}+\mathrm{HAc}=0+1000 \mathrm{mg} / \mathrm{L}$ & 0.90 & 0.10 & 191 & 1.00 \\
\hline
\end{tabular}




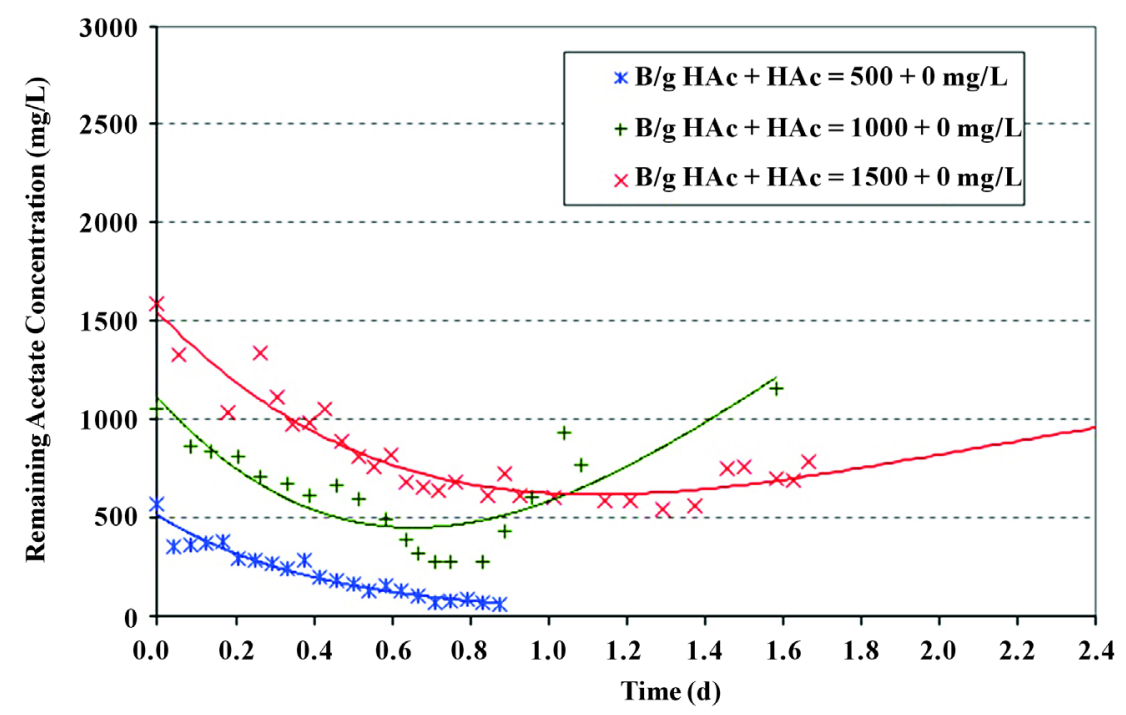

Figure 4. Progress curve of acetate degradation with different background acetate (B/g HAc).

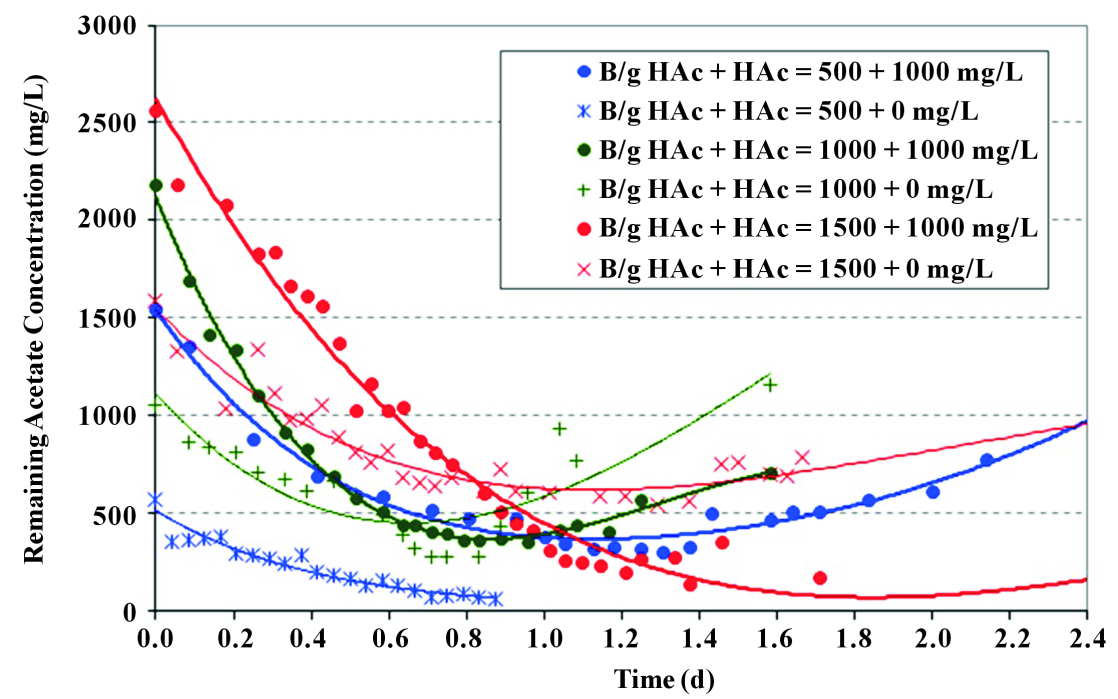

Figure 5. Progress curve of acetate degradation with and without added acetate (HAc).

salts [31]. Acetate that was naturally found in the system was the accumulation of acetate from acetic acid produced through acidogenesis, as well as the anion parts of the acetate salts. Acetate that was added into the system was solely from the dissociation product of added acetic acid. Thus, with regard to lower degradation rate indicated by the $r_{\max }$ and $K_{s}$ values with the presence of background acetate, it can be postulated that the system suffered from salt toxicity caused by acetate salts. As the background acetate concentration increased, more acetate salts were formed, and contributed to the slowing down of the degradation process. However, the toxicity effect was not detrimental as the system was still able to degrade the acetate, though not as fast as the system without acetate salts.

Another observation from Figure 6 was the inability of the system with salt-originated-acetate or background acetate (B/g HAc) to utilize the acetate to a very minimal or almost negligible content, in comparison to almost complete acetate utilization found in the system with acetic acid-originated-acetate (HAc). This is due to the inability of the salt-originated-acetate to completely dissociate itself at the experimental conditions thus making the acetate anion not readily available for consumption by the methanogens, as opposed to acetic acid-originated-acetate that dissociated more readily at the experimental conditions hence explaining the almost complete utilization of acetate. In terms of inhibitory condition, it was observed that the presence of salt-originated acetate, 


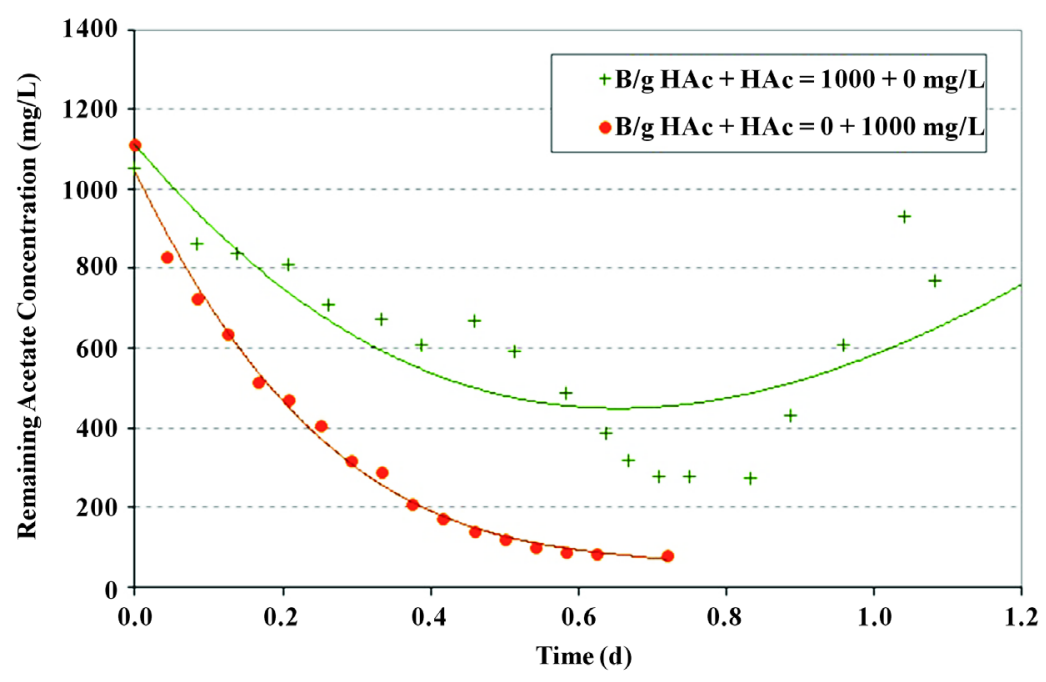

Figure 6. Progress curve of acetate degradation considering background acetate and added acetate.

which contributed to $52 \%$ to $71 \%$ reduction in acetate degradation process, could not be considered as completely inhibitory as there was still utilization of acetate at a lower rate.

\subsection{Methanogen Count of Anaerobic Digester at $45^{\circ} \mathrm{C}$}

Methanogen Illumina Assay of the sludge from the $45^{\circ} \mathrm{C}$ anaerobic digester verified the presence of the presumptive methanogens. Methanosarcinaceae, a methanogen from mesophilic group was the dominant methanogen found in the system. Comparing the $K_{s}$ value of the kinetic experiment (Run 4: B/g HAc + HAc $=0+$ $1000 \mathrm{mg} / \mathrm{L}$ ) with $K_{s}$ values of two dominant mesophilic methanogens, Methanosarcinaceae with $K_{s}$ of approximately $200 \mathrm{mg} / \mathrm{L}$ as HAc and Methanosaetaceae with $K_{s}$ of approximately $30 \mathrm{mg} / \mathrm{L}$ as HAc [15], revealed that the methanogens of the $45^{\circ} \mathrm{C}$ AD system belong to Methanosarcinaceae type. Since the methanogens were able to survive high temperature condition, the said methanogens were probably the thermo-tolerant Methanosarcinaceae. Further assay, which demonstrated that Methanosarcinaceae existed in significant numbers of $82.47 \%$ in the digester, confirmed the findings.

\section{Conclusion}

Anaerobic digesters operated at $45^{\circ} \mathrm{C}$ for more than 2 years demonstrated high biogas production with methane content of $62 \%-67 \%$. The system was able to achieve $47.8 \%$ reduction of volatile solids and pathogen count of less than $1000 \mathrm{MPN} / \mathrm{g}$ total solids in the digester effluent, satisfying U.S. EPA Class A biosolids requirements. Although the digester showed high acetate accumulation, it was not detrimental as evidenced by adequate buffering capacity and abundant production of methane. The accumulation of acetate produced large amount of toxic salts that combined with the acetate, making them not readily available to be consumed by methanogens, and resulted in $52 \%$ to $71 \%$ reduction in the acetate degradation process. The methanogens existing in the system were mostly thermo-tolerant acetate-utilizing methanogens with $82.47 \%$ Methanosarcinaceae species.

\section{Acknowledgements}

This study was supported by a grant from the United States Department of State under the Pakistan-US Science and Technology Cooperation Program. The authors gratefully acknowledge the assistance of the staff of Blue Plains Advanced Wastewater Treatment Plant in Washington, DC, for providing the feed sludge for the digesters.

\section{References}

[1] Ariunbaatar, J., Panico, A., Esposito, G., Pirozzi, F. and Lens, P.N.L. (2014) Pretreatment Methods to Enhance Anae- 
robic Digestion of Organic Solid Waste. Applied Energy, 123, 143-156. http://dx.doi.org/10.1016/j.apenergy.2014.02.035

[2] Fang, H.H.P. and Chung, D.W.C. (1999) Anaerobic Treatment of Proteinaceous Wastewater under Mesophilic and Thermophilic Conditions. Water Science and Technology, 40, 77-84. http://dx.doi.org/10.1016/S0273-1223(99)00366-2

[3] Song, Y.C., Kwon, S.J. and Woo, J.H. (2004) Mesophilic and Thermophilic Temperature Co-Phase Anaerobic Digestion Compared with Single-Stage Mesophilic and Thermophilic Digestion of Sewage Sludge. Water Research, 38, 1653-1662. http://dx.doi.org/10.1016/j.watres.2003.12.019

[4] Zabranska, J., Stepova, J., Wachtl, R., Jenicek, P. and Dohanyos, M. (2000) The Activity of Anaerobic Biomass in Thermophilic and Mesophilic Digesters at Different Loading Rates. Water Science and Technology, 42, 49-56.

[5] Ahring, B.K. (1995) Status of Science and Application of Thermophilic Anaerobic Digestion. Water Science and Technology, 30, 241-249.

[6] Kim, M., Ahn, Y. and Speece, R.E. (2002) Comparative Process Stability and Efficiency of Anaerobic Digestion; Mesophilic vs Thermophilic. Water Research, 36, 4369-4385. http://dx.doi.org/10.1016/S0043-1354(02)00147-1

[7] Maibaum, C. and Kuehn, V. (1999) Thermophilic and Mesophilic Operation of an Anaerobic Treatment of Chicken Slurry Together with Organic Residual Substances. Water Science Technology, 40, 231-236. http://dx.doi.org/10.1016/S0273-1223(99)00389-3

[8] Golueke, C.G. (1958) Temperature Effects on Anaerobic Digestion of Raw Sewage Sludge. Sewage Industrial Wastes, 30, 1225-1232.

[9] Gao, W.J., Leung, K.T., Qin, W.S. and Liao, B.Q. (2011) Effects of Temperature and Temperature Shock on the Performance and Microbial Community Structure of a Submerged Anaerobic Membrane Bioreactor. Bioresource Technology, 102, 8733-8740. http://dx.doi.org/10.1016/j.biortech.2011.07.095

[10] Al-Maliky, S.J.B. (2010) Feasibility of Anaerobic Digestion of Flotation Skim and Its Potential as Renewable Energy Source. Journal of Sustainable Development, 3, 121-126.

[11] Peces, M., Astals, S. and Mata-Alvarez, J. (2013) Response of a Sewage Sludge Mesophilic Anaerobic Digester to Short and Long-Term Thermophilic Temperature Fluctuations. Chemical Engineering Journal, 233, 109-116. http://dx.doi.org/10.1016/j.cej.2013.07.088

[12] Rahman, M.A. and Elefsiniotis, P. (2015) The Effect of Upper Mesophilic Temperature and Feed-to-Seed Ratio on Batch Anaerobic Digestion Systems. Journal of Environmental Science and Health, Part A: Toxic/Hazardous Substances and Environmental Engineering, 45, 1126-1133. http://dx.doi.org/10.1080/10934529.2010.486346

[13] Yu, J., Zheng, M., Tao, T., Zuo, J. and Wang, K. (2013) Waste Activated Sludge Treatment Based on Temperature Staged and Biologically Phased Anaerobic Digestion System. Journal of Environmental Sciences, 25, 2056-2064. http://dx.doi.org/10.1016/S1001-0742(12)60266-6

[14] USEPA (1994) A Plain English Guide to the EPA Part 503 Biosolids Rule. EPA/832/R-93/003, United States Environmental Protection Agency, Office of Wastewater Management, Washington DC.

[15] Speece, R.E. (2008) Anaerobic Biotechnology and Odor/Corrosion Control for Municipalities and Industries. Archae Press, Nashville.

[16] APHA (2012) Standard Methods for the Examination of Water and Wastewater. 22nd Edition, American Public Health Association, Washington DC.

[17] USEPA (2006) EPA Method 1680: Fecal Coliforms in Sewage Sludge (Biosolids) by Multiple-Tube Fermentation Using Lauryl Tryptose Broth (LTB) and EC Medium. United States Environmental Protection Agency, Office of Wastewater Management, Washington DC.

[18] Smith, H.S., McCarty, P.L. and Kitanidis, P.K. (1998) Spreadsheet Method for Evaluation of Biochemical Reaction Rate Coefficients and Their Uncertainties by Weighted Nonlinear Least-Squares Analysis of the Integrated Monod Equation. Applied and Environmental Microbiology, 64, 2044-2050.

[19] Shuler, M.L. and Kargi, F. (2002) Bioprocess Engineering Basic Concepts. Prentice Hall International, Englewood Cliffs.

[20] Gerardi, M.H. (2003) The Microbiology of Anaerobic Digesters. John Wiley \& Sons, Inc., Hoboken. http://dx.doi.org/10.1002/0471468967

[21] McCarty, P.L. (1964) Anaerobic Waste Treatment Fundamentals-Part Three-Toxic Materials and Their Control. Public Works, 95, 91-94.

[22] Braun, R., Huber, P. and Meyrath, J. (1981) Ammonia Toxicity in Liquid Piggery Manure Digestion. Biotechnology Letter, 3, 159-164. http://dx.doi.org/10.1007/bf00239655

[23] McCarty, P.L. (1964) Anaerobic Waste Treatment Fundamentals-Part Two-Environmental Requirements and Control. Public Works, 95, 123-126. 
[24] McCarty, P.L. (1964) Anaerobic Waste Treatment Fundamentals—Part Four-Process Design. Public Works, 95, 9599.

[25] McCarty, P.L. and McKinney, R.E. (1961) Volatile Acid Toxicity in Anaerobic Digestion. Journal of Water Pollution Control Federation, 33, 223-232.

[26] Zhao, Q. and Kugel, G. (1996) Thermophilic/Mesophilic Digestion of Sewage Sludge and Organic Wastes. Journal of Environmental Science and Health, 31, 2211-2231. http://dx.doi.org/10.1080/10934529609376487

[27] USEPA (2003) Environmental Regulations and Technology: Control of Pathogens and Vector Attraction in Sewage Sludge. EPA/625/R-92-013, Washington DC.

[28] Han, Y. and Dague, R.R. (1997) Laboratory Studies on the Temperature-Phased Anaerobic Digestion of Domestic Primary Sludge. Water Environment Research, 69, 1139-1143. http://dx.doi.org/10.2175/106143097X125885

[29] Wang, Y., Zhang, Y., Wang, J. and Meng, L. (2009) Effects of Volatile Fatty Acid Concentrations on Methane Yield and Methanogenic Bacteria. Biomass and Bioenergy, 33, 848-853. http://dx.doi.org/10.1016/j.biombioe.2009.01.007

[30] Izumi, K., Okishio, Y.K., Niwa, C., Yamamoto, S. and Toda, T. (2010) Effects of Particle Size on Anaerobic Digestion of Food Waste. International Biodeterioration \& Biodegradation, 64, 601-608. http://dx.doi.org/10.1016/j.ibiod.2010.06.013

[31] McCarty, P.L. and McKinney, R.E. (1965) Salt Toxicity in Anaerobic Digestion. Journal of Water Pollution Control Federation, 33, 399-415. 